\title{
AS RELAÇÕES INTERNACIONAIS E O DIREITO DIANTE DE UMA DISCIPLINA CONJUNTA, A PARTIR DOS MECANISMOS DE INDUÇÃO AO CUMPRIMENTO DAS NORMAS INTERNACIONAIS
}

\section{LAW AND INTERNATIONAL RELATIONS FACING A JOINT DISCIPLINE, FROM INTERNATIONAL LEGAL COMPLIANCE}

Fernando Lopes Ferraz Elias ${ }^{*}$

\begin{abstract}
RESUMO: a finalidade deste artigo é avaliar a possibilidade da construção de uma disciplina conjunta entre o Direito e as Relações Internacionais. Inicialmente, destacamos os dilemas e os desafios de uma eventual fusão interdisciplinar. A seguir, consideramos as possibilidades e perspectivas de um diálogo entre as duas áreas. Ao final, investigamos o método aplicado ao estudo do Direito e das Relações Internacionais. Constatamos que obstáculos epistemológicos e metodológicos impedem uma integração completa entre o Direito e as Relações Internacionais. Entretanto, a fim de se investigar a influência das normas internacionais no comportamento dos atores internacionais, descortina-se um novo campo empírico para o Direito Internacional, a partir da aplicação dos métodos das Ciências Sociais e da revisão da teoria das relações internacionais. Não há que se buscar uma teoria geral do Direito Internacional e das Relações Internacionais, senão uma agenda de pesquisa colaborativa, pautada num vocabulário comum entre ambas as disciplinas.
\end{abstract}

PALAVRAS-CHAVE: Relações Internacionais. Direito Internacional. Disciplina comum. Mecanismos de indução ao cumprimento das normas internacionais.

ABSTRACT: The purpose of this article is to assess the possibility of building a joint discipline between Law and International Relations. Initially, we highlight the dilemmas and challenges of an eventual interdisciplinary fusion. We next consider the possibilities and prospects of a dialogue between the two areas. At the end, we investigate the method applied to the study of Law and International Relations. We found that epistemological and methodological obstacles prevent a complete integration between Law and International Relations. However, in order to investigate the influence of international norms on the behavior of international actors, a new empirical field for International Law is being uncovered, from the application of Social Sciences' methods and the revision of international relations theory. We should not seek a general theory of International Law and International Relations, but a collaborative research agenda, based on a common vocabulary between the two disciplines.

KEYWORDS: International Relations. International Law. Common Discipline. International Legal Compliance.

\footnotetext{
* Graduado em Direito e em Relações Internacionais pela Pontifícia Universidade Católica de São Paulo (1998) e Mestre em Relações Internacionais pela Universidade do Sul de Santa Catarina, Campus Florianópolis (2002). Doutorando em Direito pelo Centro Universitário de Brasília. E-mail: flfe@ig.com.br
} 


\section{INTRODUÇÃO}

O direito e as relações internacionais são duas disciplinas separadas pelos mesmos assuntos. Essa provocação mostra mais do que aquilo que busca esconder: há óbices em se pensar ambas as áreas conjuntamente. Diferentes ontologias, procedentes de pressupostos epistemológicos divergentes, que empregam uma ampla gama de métodos distintos e são aplicadas a escolas acadêmicas concorrentes. Tudo isso torna a tarefa muito difícil. Não por acaso é ainda muito reduzida a quantidade de estudos, baseados em uma efetiva integração entre o direito e as relações internacionais, que procuram demonstrar condutas estatais determinadas por regras internacionais.

Todavia, as iniciativas nesse sentido são crescentes e passam pela elaboração de novos paradigmas. Há, hoje, um novo caminho empírico na erudição jurídica internacional. Condôminos de um mesmo território intelectual - a cooperação internacional -, a construção de um campo interdisciplinar é catalisada não por elementos de vontade ou oportunidade, mas certamente por elementos de racionalidade e necessidade decorrentes de dinâmicas intradisciplinares. E as ferramentas para a consecução desse escopo são metodológicas.

A título de uma adequada reflexão sobre a prática internacional, especificamente, um caminho interessante para se pensar a teoria do direito internacional parece ser aquele que combina os indispensáveis trabalhos práticos - a análise empírica por meio de dados quantitativos, estatísticas técnicas, estudos comparativos e exame de casos concretos (consoante uma ideia norteamericana de que uma teoria deve apresentar proposições gerais testáveis e verificáveis) - com a devida revisão da teoria das relações internacionais.

\section{DILEMAS E DESAFIOS PARA A CONSTRUÇÃO DE UMA DISCIPLINA CONJUNTA ${ }^{1}$}

Quanto progresso foi feito nas últimas duas décadas a fim de preencher as lacunas entre o direito internacional e as relações internacionais? Várias reivindicações foram feitas, mas poucas evidências sistemáticas foram obtidas, incapazes de documentar a forma e a profundidade da interface existente entre ambas as disciplinas (IRISH; KU; DIEHL, 2013, p. 359-360). O maior obstáculo repousa no fato de que qualquer tentativa de mapear um campo, conquanto vagamente, é obrigada a ser tanto excludente quanto subjetiva (SLAUGHTER; TULUMELLO; WOOD, 1998, p. 369).

\footnotetext{
${ }^{1}$ A expressão joint discipline é atribuída a Abbott e compreende a proposta de uma agenda comum sobre cooperação internacional. Cf. ABBOTT, 1992.
} 
Acadêmicos do direito internacional e das relações internacionais perseguem interesses paralelos, todavia, separados em suas pesquisas. ${ }^{2}$ A aproximação entre ambos ainda está por ocorrer (MAGEN, 2006, p. 387-388). Os dois campos são notáveis por sua distância. Conquanto estudem fenômenos semelhantes, os problemas de pesquisa, métodos e resultados são distintos. Trocar ideias tem sido difícil, em parte, porque os campos são organizados em torno de objetivos diferentes e falam para públicos diferentes (HAFNER-BURTON; VICTOR; LUPU, 2012, p. 48).

Independentemente de se concentrarem em regras internacionais, os acadêmicos das relações internacionais contemporâneas abraçam diferentes ontologias, procedentes de pressupostos epistemológicos divergentes, e empregam uma ampla gama de métodos, tornando as fronteiras entre o direito internacional e as relações internacionais obscuras quando cotejadas escolas acadêmicas concorrentes, ou mesmo entre aquelas que compartilham consideráveis afinidades epistemológicas e metodológicas, pois, dentro de uma mesma corrente, há diversas vertentes. Assim, muitas vezes, as classificações acabam mais por confundir do que por esclarecer (BECK, 1995, p. 120-122).

Com efeito, é característico de grande parte da academia, nas últimas décadas, procurar novas perspectivas em disciplinas correlatas. Na busca por tais conhecimentos interdisciplinares, estudiosos acabam frequentemente adotando definições reducionistas da disciplina do outro, por não participarem ativamente dos debates dessa disciplina. No caso da visão dos cientistas sociais sobre a lei, a distorcida analogia com o direito interno ${ }^{3}$ não exclusivamente resulta somente dessas armadilhas dos estudos interdisciplinares, mas é alimentada pela deformação profissional dentro da própria disciplina do direito internacional. Essa distorção decorre da posição fortemente positivista ${ }^{4}$

\footnotetext{
${ }^{2}$ A maioria dos cientistas políticos no âmbito das relações internacionais está focada em questões tais como o papel do poder no mundo e como os Estados cooperam para gerir os problemas coletivos - por exemplo, a poluição ambiental. Nesse contexto, o direito internacional é apenas uma das muitas forças atuantes. A geração hodierna de cientistas políticos tem se concentrado fortemente no papel das instituições, porém, muitas vezes, não distingue claramente os papéis dos costumes internacionais, dos tratados internacionais (na qualidade de acordos jurídicos formais) e das organizações internacionais, a exemplo dos tribunais internacionais. Em vez disso, esses fenômenos são vagamente definidos como “instituições jurídicas”. Ademais, são ignoradas algumas questões de importância fundamental aos acadêmicos do direito internacional, tais como os procedimentos específicos para a criação, interpretação e aplicação dos tratados e das decisões judiciais internacionais (HAFNER-BURTON; VICTOR; LUPU, 2012, p. 48).

${ }^{3}$ Na realidade, a ordem jurídica internacional não é fundamentalmente vertical, ou hierárquica, como normalmente se dá internamente. Ao contrário, está estruturada horizontalmente, composta predominantemente de centros de mesma autoridade jurídica formal chamados "Estados”. Portanto, devido às diferenças entre as instituições nacionais e as da comunidade internacional, é necessário examinar o direito internacional dentro de seu contexto político próprio, ou seja, perguntar quem o estabelece, quem o invoca, em que arenas e com quais resultados; em outras palavras, como e por quem são formulados, aplicados e cumpridos, e quais os seus efeitos (KAPLAN, 1961, p. 03-06).

${ }^{4}$ Imagina-se frequentemente que o século XIX é a idade de ouro do positivismo jurídico internacional. Se por isso se entende um pensamento totalmente consensualista, a ideia é errada. Em primeiro lugar, a maioria daqueles autores preservava alguma ideia de lei natural que, embora usualmente denominada "secundária”, cumpriu uma importante função na ausência do direito positivo. Em segundo lugar, o positivismo e o naturalismo não são realmente tão distantes como costuma parecer quando se pensa no consentimento tácito, na coerência sistemática (intencional) ou na generalização do tratado. Além disso, o positivismo baseia-se no pressuposto liberal-naturalista do primado do
} 
da teoria jurídica, em boa parte dos séculos XIX e XX, de que a lei pode ser encontrada, definida e rotulada. Dessa maneira, se a lei é vista como imposição hierarquicamente ordenada para o controle social e que emana de um soberano - seja em uma teoria pura da “Grundnorm”, seja em uma teoria da "regra de reconhecimento" socialmente aceita -, a estrutura persistentemente horizontal do direito internacional será problemática. ${ }^{5} \mathrm{O}$ direito internacional ou será declarado inexistente ou o seu funcionamento terá de ser distorcido para se encaixar nesse modelo teórico (BRUNNÉE; TOOPE, 2000, p. 21-23). O paradoxo reside no fato de que, por um lado, a lei é incapaz de desempenhar qualquer função, a menos que tenha um grau de autonomia em relação a determinado comportamento estatal; por outro, não pode ser completamente independente desse comportamento, porque a lei sem relação com o poder político reduz-se à moral natural (KOSKENNIEMI, 2005, p. 19).

indivíduo sobre a sociedade, como um verdadeiro dogma (KOSKENNIEMI, 2005, p. 131-132). No século XIX, o positivismo foi o pensamento preponderante; no entanto, não foi o único, o que significa dizer que nem mesmo nesse período exerceu um monopólio das ideias. Duas correntes de pensamento podem ser destacadas: uma emergente, a escola histórica, e outra remanescente do período anterior, o direito natural. Isso explica os sólidos resultados alcançados pelo direito internacional, no século XIX, a partir da coordenação das vontades dos Estados. Contudo, é certo que o espírito tecnocrata do positivismo do século XIX orienta o direito internacional, ainda hoje, pelos caminhos, por exemplo, da codificação e da soberania (NEFF, 2010, p. 3, 17, 19, 25-26).

${ }^{5}$ De modo geral, a lógica de Kelsen postula tanto a validade formal das normas, quanto a de Hart postula a regra de reconhecimento, o que impede legitimar juridicamente redes transnacionais, à luz do positivismo clássico, salvo caso se aceite a existência de uma pluralidade de normas hipotéticas fundamentais ou de regras de validação (ELIAS, 2014, p. 118). Contudo, no século XX, os membros da "Escola de Viena", liderados por Hans Kelsen, revisaram o pensamento positivista do século XIX - em especial, a centralidade do Estado, a base consensual e os elementos pluralistas - sem abdicarem de uma visão científica geral (NEFF, 2010, p. 23-24). A existência e a fundamentação do Estado não constitui um fim em si mesmo; ao contrário, o Estado insere-se em uma comunidade de Estados soberanos, a comunidade internacional. Consoante Kelsen: (i) o Estado nada mais é do que uma ordem jurídica reconhecida pelas demais ordens jurídicas estatais e, assim, depende de outras ordens jurídicas para existir; (ii) não há soberania ilimitada de nenhum Estado, senão limitada a um ordenamento jurídico internacional. Portanto, o próprio conceito de soberania é esvaziado na obra de Kelsen (VARELLA, 2013, p. 411-412). Desde o final da Primeira Guerra Mundial, Kelsen, em sua vasta obra de direito internacional, vislumbra a subordinação da política (relações orientadas pela força) ao direito (relações orientadas pela lei) na vida internacional, ou seja, a eliminação da guerra e o estabelecimento de uma paz duradora nas relações entre os Estados, consequência da responsabilidade de indivíduos e Estados pela violação do direito internacional e da jurisdição compulsória do judiciário internacional. A título de exemplo, a doutrina do autor distancia-se tanto do positivismo jurídico tradicional quanto de sua própria "teoria pura", quando propugna pela igualdade soberana entre os Estados como a base para o desenvolvimento do direito internacional, ao contrário de uma justificativa para a infeliz distinção entre conflitos políticos e jurídicos (KELSEN, 2008, p. 3, 23, 34, 71 e 81). Kelsen expressamente declara que se os Estados submetem um conflito à solução de um agente internacional, tenha ele ou não o caráter de um tribunal, eles estão obrigados a executar essa decisão, mesmo que não concordem com ela. Especificamente, um tribunal internacional permanente deve possuir jurisdição compulsória em todos os casos que lhe forem submetidos. Ademais, as diferenças entre disputas jurídicas e disputas políticas devem ser relativizadas porque, respectivamente, apenas se distinguem pela solução, com base ou não, em um direito pré-existente. Por isso, não há disputa que, por sua própria natureza, esteja excluída da possibilidade de solução por decisão fundada no direito internacional. E, ainda, postula que, sob a égide do direito internacional, o não cumprimento de uma decisão de um tribunal internacional constitui um delito internacional com todas as consequências que esse ato implica (KELSEN; TUCKER, 1967, p. 522, 524, 526-527, 546). 
Por essas razões, alguns acadêmicos do direito internacional entendem que a relativa autonomia de nossa disciplina deve ser zelosamente guardada, pois nem sempre a interdisciplinaridade contribui para uma melhor compreensão do direito, uma vez que parte do perigoso pressuposto de que as disciplinas são homogêneas e detalhadamente conhecidas. Todavia, geralmente o conhecimento de um estudioso de uma disciplina sobre outra área é raso e unidimensional. Portanto, apelos para um esforço interdisciplinar entre o direito internacional e as relações internacionais, conquanto louváveis em abstrato, apresentam um sério risco de reproduzirem, ou mesmo fortalecerem, configurações de poder típicas das relações internacionais (KLABBERS, 2005, p. 35-38). As relações internacionais são constituídas pela interação de forças materiais, normas e instituições. Acreditar na importância de uma estrutura comum de regras jurídicas e sociais não implica que o poder e o conflito não desempenhem o papel principal, algumas vezes mesmo dominante, nas relações internacionais (HURRELL, 2000, p. 330).

De outra banda, muitos acadêmicos do direito internacional tanto reconhecem as determinantes sociais na conduta do Estado, quanto enfatizam o papel fundamental da lei no cumprimento dos ideais normativos da “ordem mundial”. Todavia, têm dificuldade de integrar abordagens descritivas e normativas em estudos analíticos sobre o conteúdo da lei. Normalmente, a reflexão sobre a "base política” possui apenas - quando possui - consequências marginais nas elaborações doutrinárias de diferentes áreas do direito internacional. Parece que os juristas se assustaram ao verem sua metodologia e objeto específicos serem preteridos por análises políticas e sociológicas. Isso não quer dizer que os advogados devam se tornar cientistas sociais ou cientistas políticos, mas sim que sem uma melhor compreensão da teoria social e dos princípios políticos os juristas continuarão presos no cárcere da irrelevância, com um pé no pragmatismo cru e outro na indefinição teórica, vulneráveis a justas críticas (KOSKENNIEMI, 2005, p. 1, 4).

O problema é saber se a doutrina do direito internacional está preparada para transformarse, a fim de se tornar mais relevante para as relações internacionais. De fato, para um acadêmico do direito internacional, uma reconciliação entre os cônjuges rivais - direito internacional e relações internacionais - passa por atribuir à teoria das relações internacionais o papel dominante. O preço que o direito internacional paga para ser levado "a sério” pelos teóricos das relações internacionais é o de apresentar maior empirismo e ceticismo. Por um lado, é como propor a Peter Pan para absterse de voar. Jus-internacionalistas estão sendo convidados a se mudarem da Terra do Nunca para a casa de Cruella de Vil. Por outro, talvez os teóricos das relações internacionais prefiram passar os seus dias esfolando dálmatas, ao invés de passá-los tomando banho de mar e lutando contra piratas (BEDERMAN, 2001, p. 471). 
Grande parte do trabalho interdisciplinar tem sido a adoção, por parte dos juristas, de teorias, objetivos e instrumentos metodológicos das relações internacionais, e não o contrário, ou mesmo uma via de mão dupla (IRISH; KU; DIEHL, 2013, p. 367). Pois esse é um aspecto curioso da interdisciplinaridade: advogados são convidados a analisarem as relações internacionais, enquanto os acadêmicos das relações internacionais se recusam, muitas vezes, a investigarem profundamente o pensamento jurídico internacional (KLABBERS, 2005, p. 44). Não há parceria, mas sim uma forma de hegemonia por parte dos acadêmicos das relações internacionais. Os termos de troca nessa relação não são muito simétricos. O esforço supostamente colaborativo, na verdade, envolve o uso de teorias desenvolvidas nas relações internacionais para iluminar questões jurídicas internacionais. Exemplos de pesquisas interdisciplinares são trabalhos jurídicos com referência à literatura das relações internacionais; o inverso não se observa (SIMMONS, 2001, p. 276-277).

Não se deve olvidar que os estudiosos do direito e da política enfrentam uma lacuna disciplinar. Além de proporcionar-lhes uma ponte logística, precisamos encontrar e fornecer razões para atravessá-la. Sem incentivos intelectuais ou políticos para colaborar, as diferenças na produção do conhecimento e os objetivos disciplinares certamente irão mantê-los afastados, o que não seria algo inteiramente indesejável. Na verdade, há até boas razões para não sacrificar pesquisas e questões disciplinares centrais de cada área em nome de uma mera busca de maior colaboração interdisciplinar (IRISH; KU; DIEHL, 2013, p. 387). O que parecia uma parceria profícua, a fertilização cruzada entre o direito e as relações internacionais não tem se revelado algo tão profundo e está, cada vez mais, sujeita a críticas mordazes vindas de ambas as disciplinas (SIMMONS, 2001, p. 274).

Por que a dicotomia entre o direito internacional e as relações internacionais? Por que distingui-los apenas para reintegrá-los? Uma resposta é que a dicotomia reflete o quão longe a academia moveu-se do mundo que se propõe a estudar (SLAUGHTER, 2000, p. 22). A começar pelo óbvio: a nova cooperação não está claramente refletida na academia de relações internacionais. ${ }^{6}$ No início do século XXI, dos dez primeiros cursos de pós-graduação em ciência política, nos EUA, apenas três ofereciam aulas de direito internacional (SIMMONS, 2001, p. 274). A marginalidade do direito internacional percebida pelos acadêmicos e profissionais podia ser

\footnotetext{
${ }^{6}$ Um artigo de 1993 já apontava que o direito internacional evanescera dos currículos dos cursos de relações internacionais, nos Estados Unidos, no sentido de um plano de estudos integrado. Por isso, os departamentos de ciência política deixaram de oferecer aulas de direito internacional, pois seus membros não mais estavam habilitados a ministrálas. E o desaparecimento do direito internacional corresponde ao seu abandono, justamente numa era em que as dinâmicas da política internacional geraram instituições formais e informais em grande quantidade, ou seja, exatamente quando o direito internacional mais se expandiu (ONUF; TAULBEE, 1993, p. 249, 254).
} 
atribuída, em parte, à conivência da própria academia jurídica ${ }^{7}$ com a ausência da disciplina na maior parte dos currículos das escolas de direito e dos principais periódicos jurídicos. Ademais, as raras publicações eram muitas vezes limitadas a uma exposição de regras e seus significados, sem referência a qualquer contexto mais amplo ou exortações de mudança em nome da promoção do primado do direito (internacional) (TRIMBLE, 1990, p. 811, 813).

Para que haja um diálogo eficaz entre o direito internacional e as relações internacionais, acadêmicos do direito internacional ainda precisam apresentar argumentos convincentes sobre o poder do direito internacional na formação da conduta dos Estados. Isso não significa que devam demonstrar que toda norma é “jurídica”, ou seja, que apenas normas legais importam. No entanto, persiste a necessidade de mostrarem que existe uma classe de normas chamada direito internacional e que, por razões particulares, ela é possuidora de uma capacidade especial para influenciar o comportamento dos atores internacionais (BRUNNÉE; TOOPE, 2000, p. 24).

Assim, acadêmicos do direito internacional carecem de uma teoria satisfatória sobre por que e quando os Estados respeitam o direito internacional. A ausência de uma coerente teoria do comprometimento explica por que os estudiosos do direito internacional pressupõem que ele ocorra, mas não conseguem afirmar o motivo. Esse fracasso é preocupante, uma vez que o cumprimento das normas é uma das questões centrais do direito internacional. Com efeito, a falta de uma explicação para por que os Estados devem obedecer ao direito internacional, em alguns casos, mas não, em outros, ameaça minar as próprias bases da disciplina (GUZMAN, 2002, p. 1826).

Um mapa serve de metáfora para uma teoria jurídica internacional. Utilizamos diferentes mapas por diferentes razões, pois cada um contém diferentes informações. Um atlas é útil para planejarmos uma viagem, mas não para localizarmos ruas de uma cidade. Todos os mapas suprimem algumas informações a fim de destacar outras; portanto, em certo sentido, todos os mapas são incompletos - todavia, a seleção das informações relevantes é uma escolha consciente do cartógrafo. O objetivo do mapa determina o seu conteúdo. Com as teorias jurídicas acontece o mesmo: seus autores decidem os aspectos jurídicos que querem discutir e ignoram os demais. Diferentes analistas apresentam diferentes preocupações, diferentes escopos e diferentes

\footnotetext{
${ }^{7}$ Muitos acadêmicos do direito consideravam o direito internacional uma disciplina periférica, uma especialidade “acessória”, bem-intencionada, mesmo nobre, mas ingênua e em grande parte irrelevante para o mundo real. Um estudo de 1963 demonstrava que menos da metade das universidades de direito dos EUA oferecia a disciplina, em que pese, desde então, que o interesse pela área tenha crescido fortemente. Uma pesquisa com base em 3.200 artigos, publicados entre 1983 e 1985, em periódicos jurídicos, mostrava que apenas cerca de um por cento deles tratava do direito internacional, ou seja, quase nada sobre direito internacional era publicado. Mesmo nos periódicos especializados em direito internacional, a produção da área representava menos de quarenta por cento do total de artigos publicados (GAMBLE; SHIELDS, 1989, p. 39-42).
} 
pressupostos - em resumo, diferentes perspectivas - de suas ideias sobre o direito internacional (SCOBBIE, 2010, p. 59-60). Quando esses estudos em diversas áreas são reunidos, um mosaico complexo emerge: mecanismos privados e descentralizados, geralmente, são responsáveis pelo cumprimento do direito internacional. Estamos chegando a algum lugar, mas não sem resistência e não sem algumas críticas importantes do procedimento (SIMMONS, 2001, p. 274).

As principais teorias das relações internacionais oferecem explicações sobre o comportamento do Estado em determinado momento e dentro de certo regime jurídico internacional, mas nenhuma delas é capaz de fornecer um quadro global para se entender o comportamento do Estado em relação aos regimes jurídicos internacionais, em geral. As preocupações cada vez mais intensas sobre a validade do campo de pesquisa ainda não foram respondidas. É por isso que talvez não surpreenda o fato de grande parte do debate sobre o direito internacional ser polarizada e improdutiva (HATHAWAY, 2005, p. 471). De toda maneira, se entre os propósitos das relações internacionais está o de aumentar o nosso conhecimento sobre as organizações internacionais para que possamos estar em uma melhor condição de promover melhorias na ordem mundial, esse esforço foi insuficiente, a julgar pelo estado de nosso conhecimento e o estado do mundo (ROCHESTER, 1986, p. 812).

Com alguma boa vontade, é possível dizer que trabalhos acadêmicos sobre o cumprimento do direito internacional floresceram, recentemente, com importantes contribuições de estudiosos do direito, bem como de cientistas sociais, ou, ainda, como resultado de um trabalho colaborativo entre os dois. Talvez, nenhuma questão tenha atormentado uns e outros tão persistentemente como a que os desafia a demonstrar que as instituições internacionais afetam diretamente o comportamento do Estado. No entanto, apesar da crescente atenção, é ainda pequeno o número dos estudos que têm sistematicamente examinado essa questão. Ademais, o tema continua marcado por aspectos conceituais, metodológicos e teóricos que dificultam conclusões consistentes. Temos muito pouca evidência sistemática para avaliar proposições básicas sobre o porquê de os governos cumprirem as obrigações legais internacionais a que se comprometeram e se esse comportamento produz resultados relevantes (SIMMONS, 2000, p. 326, 359-360).

\section{POSSIBILIDADES E PERSPECTIVAS NA BUSCA DE UM DIÁlOgO INTERDISCIPLINAR}

A literatura florescente sobre o cumprimento das normas de direito internacional ainda está em sua infância, mas há, entre os seus acadêmicos, um interesse crescente na construção de uma 
teoria unificada, por influência de seus colegas das relações internacionais. Acadêmicos do direito internacional voltam-se para a teoria das relações internacionais para melhor explicarem modelos de evolução das normas e seu cumprimento, enquanto os acadêmicos das relações internacionais voltam-se para os modelos normativos, a fim de melhor compreenderem os comportamentos observados (ALKOBY, 2008, p. 154).

É justo dizer que uma verdadeira disciplina comum ainda não existe e pode nunca existir. Todavia, há notáveis progressos interdisciplinares realizados nos últimos anos. Equipes interdisciplinares combinam metodologias para lidar com questões complexas e um crescente número de estudiosos é treinado em ambas as disciplinas (ABBOTT, 2005, p. 9-10). Acadêmicos do direito internacional e das relações internacionais têm muito a ganhar com o desenvolvimento de uma agenda de pesquisa colaborativa que gerará novas ideias teóricas e práticas. Se não falam a mesma língua, pelo menos se comunicam. Ainda não são uma única voz e nem devem ser. Mas cada lado encontrou algo para dizer numa conversa mutuamente proveitosa (SLAUGHTER; TULUMELLO; WOOD, 1998, p. 393). Assim, a partir de temas comuns a ambas as disciplinas, a proposta interdisciplinar de Slaughter, Tulumello e Wood pretende avançar nas fronteiras entre as relações internacionais e o direito internacional; porém, não na apropriação dos conhecimentos de uma área pela outra (BADIN; SILVA; SATO, 2014, p. 15).

Por um lado, Joyner (1987, p. 386) sustenta que há pouca dúvida sobre as possibilidades de construção de uma ponte sobre o cisma intelectual que separa ambas as disciplinas. Quando a questão é tratada no nível mais elementar, torna-se uma questão mais de vontade do que de oportunidade. Por outro, Alkoby (2008, p. 154) afirma que, a partir de uma disciplina - o direito internacional -, suas incursões na outra - as relações internacionais - não são motivadas por uma tentativa de criar entre elas uma ponte ou ver como podem convergir, mas sim pela necessidade de exame crítico da influência de uma na outra, à luz do cada vez maior trânsito entre as suas fronteiras.

Da mesma forma como Miguel de Cervantes cria, de maneira caricatural, dois personagens para desmistificar as antigas histórias medievais de cavaleiros - um sonhador Dom Quixote e um pragmático Sancho Pança, que se opõem e se complementam em um típico movimento dialético, isto é, a identidade de cada um é consolidada por meio da contraposição com o outro; especificamente, entre o desejo de mudança convertido em loucura, pela perda de contato com a realidade, e o ceticismo transformado em apologia irrestrita, conquanto por vezes involuntária, das condições factuais -, o estudo interdisciplinar do direito internacional e das relações internacionais serve para revisar a historiografia de (e criticar a dicotomia entre) ambas as disciplinas. Em outras 
palavras, a oposição responsável pela própria identidade do direito internacional e das relações internacionais os torna inúteis, ora pela defesa de proposições irrealizáveis, ora pela descrição da realidade incontornável do sistema internacional que não permite nada além da mera contemplação da realidade, porquanto o “dever ser” perde a pretensão de "ser” e o que “é” torna-se impermeável àquilo que “deve ser” (SOUZA, 2006, p. 102, 150).

Recentemente, o mais significativo desenvolvimento em estudos jurídicos internacionais é, sem dúvida, o colapso da barreira intelectual entre as disciplinas de direito e relações internacionais (VERDIER, 2002, p. 840). Cientistas políticos e acadêmicos do direito internacional têm lido e citado uns aos outros com uma frequência crescente e com uma vasta gama de propósitos (SLAUGHTER; TULUMELLO; WOOD, 1998, p. 368).

Aulas de professores da faculdade de direito são oferecidas aos alunos do departamento de política, cujos professores escrevem livros que, por sua vez, são adotados no curso de direito (HATHAWAY; KOH, 2005). A disciplina de ciência política desenvolveu um proativo programa de pesquisa sobre o desenvolvimento, funcionamento, disseminação e impacto das normas jurídicas, dos acordos e das instituições no plano internacional. Enquanto isso, um número crescente de acadêmicos do direito internacional desenvolveu um interesse pela pesquisa e pelos métodos da ciência política. Por mais de duas décadas, ambos vem colaborando e compartilhando ideias (HAFNER-BURTON; VICTOR; LUPU, 2012, p. 47-48).

O “direito internacional empírico”, na expressão de Ginsburg e Shaffer (2009, p. 3), deve continuar a ser um campo interdisciplinar distinto e que leva a sério tanto o direito quanto a política. Acima de tudo, direito internacional e política internacional coabitam o mesmo espaço conceitual. Juntos, eles integram as regras e a realidade do sistema internacional, uma construção intelectual que advogados e cientistas políticos usam para descrever o mundo que estudam e buscam manietar. Como um destacado grupo de acadêmicos do direito internacional e um crescente número de cientistas políticos reconhecem, faz pouco sentido estudar as duas disciplinas separadamente (SLAUGHTER, 1995, p. 503). Da mesma forma que advogados constitucionalistas estudam a teoria política e os teóricos políticos inquirem sobre a natureza e a substância das constituições, assim também as duas disciplinas que estudam as leis do comportamento estatal devem procurar aprender uma com a outra. ${ }^{8}$ No mínimo, devem aspirar a um vocabulário comum e a um quadro de análise que permita o compartilhamento de ideias e informações (BURLEY, 1993, p. 205).

\footnotetext{
${ }^{8} \mathrm{O}$ estudante de direito e o estudante de política olham para o mesmo mundo do ponto de vista de importantes disciplinas. É uma pena, na verdade, uma grande perda, que um não ouça o outro (HENKIN, 1979, p. 4).
} 
O direito internacional e as relações internacionais descrevem os mesmos fenômenos: práticas estatais e estruturas formais de instituições e regras internacionais, mesmo que isso não seja um fim em si mesmo (ABBOTT, 1992, p. 168). Destarte, ambas as disciplinas dividem os mesmos interesses centrais: a paz e a cooperação internacionais. Portanto, aquela disseminada insularidade acadêmica não deve mais prosseguir. As relações internacionais não podem se limitar aos estudos racionalistas dos regimes, e tampouco o direito internacional às análises jurídicas positivistas ${ }^{9}$ da doutrina e da prática estatal (BECK, 1995, p. 120-122). Cada disciplina tem muito a contribuir com a outra. Por um lado, o direito internacional pode oferecer grande quantidade de informações sobre as regras e as instituições jurídicas, matéria-prima para o desenvolvimento e aplicação da teoria. Por outro, as relações internacionais possibilitam uma fuga do estreito positivismo (ABBOTT, 1989, p. 340).

Cientistas políticos dedicados aos assuntos internacionais podem contribuir para o estudo da lei internacional e, por sua vez, o conteúdo e o processo do direito internacional podem melhorar as ambições de pesquisa dos especialistas em relações internacionais (JOYNER, 1987, p. 386). Os estudiosos estarão mais bem equipados se explorarem as diferenças existentes nos modelos teóricos, especialmente no contexto da construção de políticas e arranjos institucionais (ABBOTT, 2005, p. 33-34). A fusão interdisciplinar das relações internacionais com o direito internacional fornece a base para o desenvolvimento mais forte e eficaz das instituições internacionais. Portanto, os benefícios da pesquisa interdisciplinar não são apenas teóricos, mas também práticos (ACEVES, 1997, p. 266).

Os juristas muitas vezes desconfiam da parcimônia dos modelos teóricos das relações internacionais. No entanto, esses modelos têm funções importantes não apenas para os cientistas políticos. Os juristas podem usá-los não só para diagnosticar problemas políticos, mas também para gerar uma gama de soluções jurídicas. O conhecimento das relações internacionais pode ajudar os acadêmicos do direito internacional sobre a melhor forma de atingir um determinado objetivo ou sobre quais objetivos são de fato viáveis. Qual deve ser a relação entre a paz, a ordem, e os objetivos humanitários? Até aonde vai o direito de um povo à autodeterminação? Como escolher entre o aumento da proteção ambiental e a promessa de tirar milhões de pessoas da pobreza? Deve a

\footnotetext{
${ }^{9}$ As normas internacionais são vistas como produtos do interesse dos Estados, a partir de escolhas racionais em um mundo descentralizado (ABBOTT, 1992, p. 168). Para Goldsmith e Posner (2005, p. 13 e 225), os Estados cumprem o direito internacional não pelo fato de ele ter sido internalizado ou por sua força moral, mas simplesmente porque agem por interesse próprio. O direito internacional não tem força para conduzir os Estados a cumprirem um compromisso contrário aos seus interesses. Por isso, conquanto o direito internacional seja um fenômeno real, os juristas tendem a exagerar o seu poder e significado.
} 
Organização Mundial do Comércio institucionalizar o livre comércio ou o comércio justo? (SLAUGHTER, 2000, p. 191-192, 234-235).

Considerando a produção acadêmica estrangeira ${ }^{10}$, observa-se um aumento do interesse pela colaboração interdisciplinar entre os membros de ambas as disciplinas. Um crescente número de acadêmicos do direito internacional utiliza modelos teóricos, ferramentas metodológicas, prescrições políticas e/ou dados empíricos das relações internacionais, enquanto um crescente número de acadêmicos das relações internacionais consideram o direito internacional e as organizações internacionais formais dignos de atenção. Essa colaboração decorre tanto das mudanças ocorridas na política mundial e a consequente necessidade desses acadêmicos de explicarem e moldarem esses desenvolvimentos no ambiente externo, quanto de diversas dinâmicas intradisciplinares, ou seja, dinâmicas intelectuais internas a cada disciplina. Assim, a partir do ponto de vista de suas respectivas disciplinas, cada lado utiliza conscientemente abordagens interdisciplinares. Em suma, as razões da antiga divergência, bem como da nova convergência, têm mais a ver com a internalização de eventos externos, como a Guerra Fria e seu ocaso ${ }^{11}$, e com a externalização de dinâmicas internas de teorias construídas e paradigmas alterados (SLAUGHTER; TULUMELLO; WOOD, 1998, p. 370-371, 373 e 393).

Podem ser identificados pontos em comum de certos fenômenos de interesse compartilhado entre ambas as disciplinas. ${ }^{12}$ O exemplo mais notável é o do comprometimento com

\footnotetext{
${ }^{10}$ Em seus primeiros artigos a respeito da interdisciplinaridade entre as relações internacionais e o direito internacional, como parte de um movimento muito forte na academia norte-americana - o de profissionalização e criação de nichos acadêmicos -, Slaughter procura criar um novo espaço acadêmico para si. Por consequência, recebeu forte crítica de que tal abordagem seria relevante exclusivamente nos Estados Unidos. Na verdade, sua reflexão a respeito dos instrumentos e agentes do sistema global, conceitos e formas de interação sobre esse sistema, parte do contexto estadunidense (BADIN; SILVA; SATO, 2014, p. 20, 22). Para Koskenniemi (2000, p. 29-32), não há dúvida de que o chamado acadêmico para se integrar as relações internacionais e o direito internacional é uma cruzada norte-americana, cuja lógica do argumento cria uma imagem funcionalista do direito internacional - que o deforma e o instrumentaliza como ferramenta do poder, comprometida com o liberalismo e preocupada em justificar a hegemonia norte-americana e propagar os seus valores. A título de exemplo, no Reino Unido não se observa uma separação entre os acadêmicos das relações internacionais e os do direito internacional. A “Escola Inglesa” trabalha de acordo com a tradição grociana, ou seja, considera o papel das normas na sociedade internacional (BECK, 2009, p. 14). Todavia, desde os trópicos, não há como pensar uma agenda interdisciplinar sem dialogar com a produção acadêmica estrangeira; particularmente, sem a contribuição do caminho percorrido por Slaughter. No Brasil, os dois campos de pesquisa - relações internacionais e direito internacional - ainda são muito dependentes das categorias decursivas do debate científico estrangeiro e, portanto, carecem não apenas de categorias específicas, mas de um maior número de estudos contextualizados (BADIN; SILVA; SATO, 2014, p. 22).

${ }^{11}$ Ao final da Guerra Fria, a proposta de uma agenda crítica unindo teóricos do direito internacional e das relações internacionais apresentou-se como um caminho para a regulação jurídica do exercício do poder, de acordo com padrões socialmente toleráveis, a fim de se diminuir a violência da cena internacional (SOUZA, 2006, p. 157-158).

${ }^{12}$ Slaughter, Tulumello e Wood (1998, p. 384-385 e 393) identificam três áreas de convergência - com pressupostos parecidos sobre o sistema internacional e temas similares - que podem ser proveitosamente exploradas pelos acadêmicos tanto das relações internacionais quanto do direito internacional: a "teoria da governança global”, a construção social das normas compartilhadas e a "teoria da ação liberal”. Esse mapeamento da interdisciplinaridade
} 
as obrigações internacionais (IRISH; KU; DIEHL, 2013, p. 365). Recursos intelectuais substanciais têm sido canalizados nos últimos anos para o estudo do comprometimento do Estado, um movimento semelhante a uma mudança de paradigma em termos da profunda reorientação teórica observada (MUSHKAT, 2010, p. 162).

Para Jacobson (1982, p. 316, 320, 324), há um amplo consenso, como jamais houve, sobre os objetivos normativos da política internacional e sobre as características de uma ordem mundial desejável. Esse consenso se estende para as metas relacionadas à situação dos indivíduos e inclui um acordo sobre os elementos essenciais da dignidade humana e da justiça, na medida em que ambos são percebidos no contexto do sistema global. Dessa maneira, os Estados têm aceitado as normas incorporadas nesse consenso como objetivos legítimos de política internacional e nacional e como a definição oficial da condição adequada dos indivíduos em uma ordem mundial desejável; portanto, a questão não é saber se eles devem ou não ser concretizados, mas sim como fazê-lo de maneira mais eficaz.

Nesse diapasão, por um lado, as normas que regulam o uso da força e as organizações incumbidas de garantir a segurança internacional deveriam ser reformuladas - por exemplo, de acordo com a polaridade das relações internacionais, se fosse possível demonstrar, com segurança, que a existência de grandes potências é a melhor garantia de paz internacional. Por outro, se a lei seja internacional, transnacional ou puramente nacional - faz com que os Estados ajam de uma maneira diferente daquela diretamente derivada do poder e da busca pelos interesses nacionais, então os modelos desenvolvidos por cientistas políticos deveriam ser revistos em conformidade com essas variáveis legais (BURLEY, 1993, p. 206).

\section{O MÉTODO APLICADO AO ESTUDO DO DIREITO E DAS RELAÇÕES INTERNACIONAIS}

Há uma divisão metodológica que separa direito e política. Primeiro, ao contrário de seus colegas das relações internacionais, o objetivo tradicional dos acadêmicos do direito internacional não é explicar o comportamento dos Estados, mas sim determinar quais regras possuem o status de direito. ${ }^{13}$ Segundo, a abordagem jurídica é essencialmente prescritiva, isto é, defende o que a lei

\footnotetext{
sobrepõe (mas também transcende) os paradigmas institucionalista, construtivista e liberal das relações internacionais. As relações internacionais e o direito internacional redescobriram-se. Uma nova geração de acadêmicos interdisciplinares surgiu, reconhecendo que ambas as disciplinas representam diferentes faces e perspectivas dos mesmos fenômenos empíricos e intersubjetivos.

${ }^{13}$ A principal tarefa dos acadêmicos do direito internacional é determinar a existência e o conteúdo das regras e como elas são aplicadas em situações específicas. Quando atuam como juízes ou árbitros, comparecem perante cortes ou
} 
deve ser, em vez de descrever o que é (IRISH; KU; DIEHL, 2013, p. 362). Nas palavras de Keohane (1997, p. 488), duas “óticas” diferentes sobre fenômenos semelhantes, a ótica instrumentalista das relações internacionais e a ótica normativa do direito internacional.

Os estudiosos dos dois campos foram separados por suas metodologias. Os cientistas políticos comprometidos com um programa de pesquisa empírico sobre o comportamento real dos Estados e, em muitos casos, os acadêmicos do direito internacional envolvidos em um projeto normativo para demonstrar a existência de regras no plano internacional. Se o projeto normativo que é central para o direito internacional estiver mais intimamente ligado ao projeto empírico dos estudiosos das relações internacionais, ambos podem ser enriquecidos no sentido de se identificar as regras que facilitem ou incentivem comportamentos estatais na seara global (KRASNER, 2000, p. 98-99). Um discurso interdisciplinar pode levantar novas questões teóricas e, ainda, apresentar relações empíricas perdidas em “campos de estudo” presumidamente bem-definidos (KRATOCHWIL, 1999, p. 1). Sem dúvida, seria vantajoso aos acadêmicos das relações internacionais e do direito internacional dedicar mais atenção aos aspectos da interface entre a política internacional e o direito internacional (BYERS, 2001, p. 20).

O debate sobre a teoria ${ }^{14}$ do direito internacional tornou-se marginalizado. Isso nem sempre foi assim. No início, escritores como Vitória, Suarez ou Grotius analisavam o direito internacional sem diferenciarem o concreto do abstrato, a descrição da prescrição. O padrão acadêmico jurídico pós-iluministas separa, metodologicamente, a “teoria” da “doutrina”. Não que isso prejudique automaticamente a teoria, mas distancia o que os estudiosos dizem sobre a ordem mundial ou a justiça internacional, por um lado, e sobre os princípios e regras jurídicas “válidas”, por outro. Supõe-se, implicitamente, que os problemas da teoria não são problemas e que as questões normativas e sociológicas de ordem mundial podem ser mais bem tratadas por meio da análise da lei válida feita pela doutrina. Eis o dilema: A fim de evitar os problemas de teoria, o jurista recuou para a doutrina. Mas a doutrina reproduz problemas capazes de solução apenas a partir de uma posição teórica. Portanto, é preciso superar a dicotomia teoria/doutrina, pois em cada teoria há uma concepção específica de doutrina normativa e cada doutrina normativa necessariamente assume uma teoria (KOSKENNIEMI, 2005, p. 1-4).

tribunais, ou aconselham governos e particulares, e espera-se que eles expliquem a lei e não, na maioria dos casos, como a lei é desenvolvida, mantida e transformada. Portanto, talvez seja compreensível que a maioria dos acadêmicos da área tenha o mesmo foco (BYERS, 2001, p. 48).

${ }^{14} \mathrm{Na}$ verdade, o termo "teoria” tem sido utilizado de muitas maneiras diferentes na literatura do direito internacional. A variedade de significados atribuídos à expressão pode ser atribuída, fundamentalmente, a diferentes percepções da natureza da própria lei internacional (JOHNSTON, 1988, p. 3). 
Na verdade, hoje, uma grande parte das discussões teóricas do direito internacional reflete a assimetria do sistema jurídico internacional. Não surpreende que, à parte a tendência mais idealista do sistema internacional, considerável parcela da teoria jurídica internacional seja instrumental, isto é, voltada a esclarecer e explicar o papel e o comportamento dos Estados na esfera internacional. E é inegável que concepções teóricas e abordagens intelectuais e/ou metodológicas influenciam a maneira como o direito internacional é entendido, utilizado e criticado (SCOBBIE, 2010, p. 61-62).

Dessa maneira, para a perfeita compreensão do relacionamento entre as regras internacionais e os comportamentos estatais e para a modificação de regimes, é necessário que as teorias do direito internacional sejam submetidas à análise empírica por meio de ferramentas metodológicas das ciências sociais, incluindo múltiplas estatísticas, análises comparativas criteriosas e estudos de caso detalhados, a fim de desenvolverem proposições gerais testáveis e verificáveis (BRADFORD, 2004, p. 380-381). É preciso reabilitar o status do direito internacional na comunidade da ciência política, por meio de uma nova metodologia do direito internacional a partir da análise empírica de dados e, assim, de um novo exame de certos princípios fundamentais do direito internacional (AREND, 1999). Nessa empreitada, são fundamentais: o conceito de conformidade como um fenômeno testável, o modelo de experimentos para testar as relações causais entre os regimes jurídicos e condutas dos Estados, a seleção e aplicação de métodos analíticos para avaliar os dados pertinentes ao comprometimento, a sistemática e rigorosa interpretação dos resultados da pesquisa, a validação dos dados, métodos e conclusões, e a articulação e avaliação de conhecimentos almejados (BRADFORD, 2005, p. 497).

Uma vez que o esforço em compreender a questão da conformidade é interdisciplinar envolvendo juristas, sociólogos e cientistas políticos -, diferentes métodos de análise, raciocínio e padrões de prova são responsáveis pela natureza díspar da literatura (SIMMONS, 1998, p. 77). Portanto, uma barreira que muitas vezes impede novas abordagens para o estudo do problema do cumprimento das normas internacionais é de ordem metodológica: juristas internacionalistas e teóricos das relações internacionais frequentemente lidam com o mesmo assunto, mas raramente se esforçam para usar as teorias e metodologias do outro (TAUBMAN, 2004, p. 222).

Nessa esteira, Abbott (2004, p. 127-128) postula que as relações internacionais compreendem um vasto campo, com diversas abordagens teóricas distintas, mas não podem ser reconhecidas como um “método jurídico”, em sentido estrito, capaz de responder questões da doutrina do direito. Já para Keohane (1992, p. 176), há sutis diferenças entre as relações internacionais e o direito internacional, menores quanto à natureza dos problemas e maiores quanto 
ao enfoque dado pelos acadêmicos de cada área. Assim, o autor aplica o método das ciências sociais, primordialmente explicativo, ao conteúdo jurídico da obrigatoriedade das normas, de cunho prescritivo, a fim de que, por meio da integração das duas disciplinas, seja avaliada a possibilidade de construção de uma disciplina conjunta, a partir da análise de pontos inter-relacionados.

A seu turno, Rochester (1986, p. 812) propõe um modesto primeiro passo, uma concepção de organização internacional que a distinga claramente de outros fenômenos das relações internacionais. No léxico contemporâneo, as organizações internacionais poderiam ser vistas como um conjunto de instrumentos para a tomada e implementação de “políticas transnacionais” ou “políticas públicas internacionais”, e não apenas como um conjunto de interações internacionais que seguem um modelo. Concebê-las dessa forma não violaria quaisquer cânones científicos; além disso, adicionaria clareza conceitual e facilitaria a expansão do conhecimento sobre as dinâmicas de construção institucional internacional. Ademais, permitiria uma visão mais ampla da ordem mundial não apenas aos acadêmicos, mas também aos práticos. Essa proposta não apelaria para ideologias ou visões particulares de mundo, tampouco incitaria um otimismo dotado da vontade de ignorar os defeitos ou efeitos hostis de algumas instituições; ao contrário, somente demandaria uma análise mais focada das estruturas e processos associados a essas instituições, o que tanto pode revelar problemas quanto possibilidades. Tal compromisso poderia assumir a forma de, por exemplo, críticas severas a certos procedimentos de votação, baseadas em análise sistemática e levando a recomendações prescritivas.

O século XX revelou duas transformações fundamentais e inseparáveis no campo das relações internacionais: a influência de normas e instituições internacionais em novas áreas e o advento de inovações teóricas, responsáveis por novas maneiras de se pensar essas áreas, isto é, métodos que se distinguem das abstratas teorias do direito internacional que explicam a sua natureza, mas não se limitam à aplicação a casos práticos. Em outras palavras, esses métodos ${ }^{15}$ focam não a coerência de uma teoria específica em explicar os fundamentos e traços do direito internacional, senão sua relevância para advogados e acadêmicos diante de questões contemporâneas concretas (o que não se traduz numa mera distinção entre teoria e prática), uma vez

\footnotetext{
${ }^{15}$ Ratner e Slaughter enquadram o debate sobre a interdisciplinaridade como um dos métodos em Direito Internacional, ao lado de seis outros métodos relevantes: i) o positivismo jurídico; ii) a escola procedimental de New Haven; iii) a do Direito Internacional como processo; iv) os estudos críticos em Direito; v) a filosofia feminista; e vi) o debate sobre Direito e Economia. Mais tarde, isso passou a ser reproduzido por outros acadêmicos norte-americanos (BADIN; SILVA; SATO, 2014, p. 16).
} 
que não há teoria do direito internacional sem a análise de problemas concretos (RATNER; SLAUGHTER, 2004, p. 1, 3-4).

A integração acadêmica entre o direito e as relações internacionais é uma afirmação do direito internacional como um empreendimento tanto intelectual quanto prático. É o corolário natural da indivisibilidade da lei e da política, insistindo que esforços normativos para induzir ou alterar comportamentos residem em pressupostos explicitamente articulados sobre as causas ou a natureza desse comportamento (SLAUGHTER; TULUMELLO; WOOD, 1998, p. 372). Toda lei tem uma dimensão política, uma vez que busca fornecer modelos oficiais de como os particulares devem se comportar (SCOBBIE, 2010, p. 60). É impossível estudar o direito fora do seu contexto político. A política permeia o direito, mesmo que ele, de maneira compreensível e necessária, evitea. E no direito internacional - talvez até mais do que no direito interno - a política, a economia e mesmo as relações culturais e sociais entre os Estados definem o que deve e o que pode ser regulamentado (SLAUGHTER, 2000, p. 21).

O direito e a teoria jurídica não existem num vácuo de valores; ao contrário, referem-se, inevitavelmente a condições políticas. Os contornos da análise jurídica de uma questão são determinados por valores políticos. Todavia, isso não implica o inexorável colapso do direito em política. Fatores são avaliados para se decidir o que o direito deve ser, e essa decisão transformada em direito (SCOBBIE, 2010, p. 69). Se é verdade que toda lei é uma “política”, é igualmente verdade que cada política pode tornar-se eficaz apenas como "lei”, de acordo com as preferências dos atores (KOSKENNIEMI, 2005, p. xiv). Nessa esteira, longe de identificar o direito internacional e a política internacional como uma única coisa, tampouco de afirmar a inexistência de uma relação entre ambos, Stern (2000, p. 252) destaca a complexidade dialética desse relacionamento; ou seja, se a lei é dependente do poder político, ela também influencia as relações de poder na sociedade. Portanto, há definitivamente uma falácia em opor direito e política. A política está presente tanto no processo de criação do direito, quanto na sua utilização; a referência à lei é um dos elementos da política.

Embora, cada vez mais, estejam disponíveis dados sobre as respostas dos Estados a regras e decisões internacionais - mormente quando há uma estrutura de monitoramento e fiscalização ou quando benefícios são auferidos pelos Estados -, em alguns casos, a escassez de bons estudos empíricos sobre a correspondência entre o comportamento estatal e as regras e decisões internacionais é um sério obstáculo para uma adequada avaliação do papel do direito 
internacional. ${ }^{16}$ Da mesma forma, um trabalho sistemático de buscar essa correspondência é irregular, conquanto estudos demonstrem a importância prática do cumprimento doméstico para os objetivos da política. O muito necessário trabalho empírico, envolvendo estudos de casos, entre outras metodologias, começa a aparecer. No entanto, como as pessoas envolvidas neste trabalho reconhecem prontamente, os obstáculos metodológicos são enormes. A caracterização em casos marginais é dificultada por problemas que acadêmicos do direito internacional enfrentam diariamente, incluindo divergências de interpretação, incertezas quanto à autoridade de diferentes fontes de direito, questões de oponibilidade e exceções à responsabilidade. Ademais, mesmo se soubéssemos o quanto o comportamento do Estado se adapta às normas internacionais, não teríamos necessariamente uma descrição de uma relação causal entre direito e comportamento (KINGSBURY, 1998, p. 347-348).

O relacionamento entre o direito, a economia e a política é notoriamente complexo. Sugerir a existência de uma relação causal entre os três é rebaixar o direito a um mero produto das forças econômicas e políticas ou criar expectativas exageradas - portanto, fadadas a fracassarem - sobre o direito como instrumento de mudança econômica e política. Ambas as estratégias cometem o mesmo erro de suposição, tanto de que os três possam ser diferenciados quanto de que simplesmente seja possível criar redes de relações causais (KOSKENNIEMI; LEHTO, 1996, p. 533).

Koskenniemi (2005, p. 58-60, 64-65, 171, 219) ressalta o dilema entre a exigência de concretude do conteúdo da lei internacional no que concerne ao comportamento, à vontade e ao interesse dos Estados, e a necessidade de normatividade relacionada com a capacidade de a lei internacional opor-se às políticas estatais. Um direito internacional, por um lado, muito concreto perde a sua natureza normativa e reduz-se a uma apologia descritiva; por outro, verdadeiramente normativo cria um fosso entre si e a prática dos Estados de forma a tornar duvidosa a objetividade do método de verificação de suas normas e, portanto, termina em uma utopia indemonstrável. A partir dessas ideias, classifica os argumentos quanto ao cumprimento das obrigações internacionais em ascendentes e descendentes, ou seja, estes se baseiam no pressuposto de que um código normativo prevalece sobre o comportamento do Estado e determina suas obrigações, enquanto aqueles se fundam na ideia de que o comportamento do Estado indica a direção que a lei

\footnotetext{
${ }^{16}$ Em muitas áreas simplesmente não há estudos sistemáticos para demostrar que a maioria dos Estados age em conformidade com a lei internacional a maior parte do tempo, e os estudos de que dispomos mostram impressões baseadas em dados não verificados, infundados, circunstanciais ou ocasionais; não necessariamente confiáveis (KINGSBURY, 1998, p. 346-347).
} 
internacional deve seguir. Ambos se acusam de subjetivismo. Do ponto de vista ascendente, o modelo descendente pressupõe a existência de uma moralidade natural e, portanto, não pode demonstrar o conteúdo de suas normas, tornando-se arbitrário. Da perspectiva descendente, o modelo ascendente privilegia o Estado em detrimento de normas objetivamente vinculativas; assim, permite ao Estado, em cada situação, escolher a lei que melhor lhe aprouver. Ou um ou outro se pretende superior. Uma posição intermediária raramente é considerada. Para o autor, o caráter objetivo do direito internacional, isto é, a sua própria relevância, depende da inclusão de uma visão na outra. Porém, sem tentar conciliá-las, sem pretendê-las uma única coisa, porque são mutuamente excludentes.

Não há e nunca haverá uma teoria do direito e das relações internacionais que consiga explicar completamente a conduta dos Estados, prevendo ações estatais específicas em circunstâncias concretas. Não podemos saber se, no futuro, as condições necessárias para a cooperação estarão presentes ou como os Estados responderão às condições existentes (GLENNON, 2005, p. 988). Apenas onde o descumprimento é generalizado, persistente e injustificável presumivelmente, em casos limites - haverá um modelo explicativo que repousa sobre um comportamento manifesto por si só (KRATOCHWIL; RUGGIE, 1986, p. 768).

A maior parte dos estudos jurídicos internacionais tem se esquivado da teorização explícita e da derivação de hipóteses. ${ }^{17}$ Na verdade, houve uma tendência de se confundir teoria e método na interpretação dos fenômenos jurídicos internacionais (IRISH; KU; DIEHL, 2013, p. 362). Parte da dificuldade no estudo empírico do cumprimento das normas internacionais tem sido metodológica. Se o problema analítico central é entender as condições sob as quais os Estados se comportam de acordo com as regras a que se comprometeram ou, mais amplamente, de acordo com as normas vigentes do direito internacional, então é importante isolar o impacto dessas regras e normas. Vários estudos tentaram demonstrar a correlação entre as normas jurídicas e comportamentos estatais - às vezes, empregando grandes bancos de dados e estatísticas técnicas -, mas a maioria não é convincente em demonstrar o nexo de causalidade, ou até mesmo uma ligação explicativa entre as medidas tomadas pelos Estados e as considerações normativas (SIMMONS, 1998, p. 89).

\footnotetext{
${ }^{17}$ A questão sobre o que deve ser considerado como teoria é controversa. Nas ciências sociais, a resposta para a questão sobre se algo deve ou não ser qualificado como teoria depende, geralmente, do local onde se pergunta. A maioria dos europeus usa o termo teoria para qualquer coisa que organize um campo sistematicamente, estruture questões e estabeleça um conjunto rigoroso e coerente de categorias e conceitos inter-relacionados. Para a maioria dos norteamericanos, entretanto, uma teoria, em regra, depende do que ela é capaz de explicar e do que seu conteúdo é capaz de gerar - hipóteses testáveis de natureza causal (BUZAN, 2006, p. 24).
} 
Recentemente, em 2013, com o objetivo de acompanhar a intersecção das duas áreas e descrever a extensão e o tipo de sua interação, um trabalho com fulcro em revistas científicas de destaque - duas de direito internacional, cinco de relações internacionais e uma interdisciplinar -, no período entre 1990 e 2010, examinou a polinização cruzada de ideias e abordagens entre ambas as disciplinas - especificamente, se os métodos das ciências sociais têm sido utilizados pelos acadêmicos de direito internacional, bem como se os estudiosos das relações internacionais têm considerado o direito internacional em suas pesquisas. Foram identificados, nesses periódicos, oitenta e sete artigos acadêmicos (em um universo de mais de dois mil artigos publicados) nas revistas científicas de ciência política e cento e noventa e seis artigos acadêmicos nos periódicos científicos jurídicos. Entre os duzentos e oitenta e três artigos produzidos sobre as questões referidas e no mencionado período de vinte anos, chama atenção a raridade de pesquisas sobre questões jurídicas nas publicações de ciência política, que representam menos de cinco por cento dos artigos acadêmicos e, ainda, estão desproporcionalmente concentradas em uma única revista. Ademais, se estudos de caso são comumente realizados em ambos periódicos científicos, o trabalho sugere que a anunciada "virada empírica” da ciência jurídica pode ter sido exagerada, uma vez que a análise estatística de dados empíricos ainda não é amplamente aceita nos círculos legais. A maior parte da pesquisa empírica em matéria de direito foi realizada em revistas científicas de ciência política, por estudiosos de relações internacionais - considerável parcela de mais de quarenta por cento dos artigos. Esse método é encontrado em menos de três por cento dos artigos em revistas científicas de direito. Destarte, constatou-se a falta de progressos traduzida nos decepcionantes resultados auferidos, insuficientes para colmatar o fosso entre os dois campos (IRISH; KU; DIEHL, 2013, p. 360, 369, 374, 377-378, 386).

Em verdade, houve poucos esforços para utilizar métodos experimentais no estudo do direito internacional. Segundo eles, há apenas um punhado de experimentos - um experimento de campo, dois experimentos de laboratório e oito experimentos de pesquisa. Além disso, cientistas políticos (e não juristas) realizaram todos esses experimentos (CHILTON; TINGLEY, 2013, p. 179182). Atualmente, as mais relevantes teorias sobre o comprometimento no direito internacional não vêm do conhecimento jurídico, mas da academia das relações internacionais, muitas vezes cética em relação à importância do direito internacional para o sistema internacional, quando não o ignora por completo. E há ainda acadêmicos que tentam demonstrar que na realidade o direito internacional não modifica o comportamento dos Estados, que são seletivos em relação aos acordos celebrados e, ademais, as políticas, quando adotadas, assim o seriam mesmo na ausência do pacto. Conquanto os pesquisadores tenham começado a usar mais os métodos empíricos, essas abordagens 
não silenciaram totalmente os críticos que são céticos quanto à disposição dos Estados a mudarem suas preferências e ações como consequência do direito internacional. Como resultado, melhorar os métodos empíricos utilizados para conduzir a análise causal é um projeto de grande importância para os estudiosos do direito internacional (GUZMAN, 2002, p. 1826-1827).

Em contraponto, outros autores afirmam que, apesar do projeto empírico ainda estar em fase inicial, ele se expande graças aos esforços de estudiosos de várias disciplinas. Como muitos outros campos do conhecimento jurídico, o direito internacional tem visto uma explosão de trabalhos empíricos nos últimos anos. Há duas décadas, o trabalho empírico sobre o direito internacional era extremamente raro. Essa mudança, há muito esperada, reflete, por um lado, a crescente influência das ciências sociais nos estudos jurídicos, e por outro, o aumento da importância e da visibilidade do direito internacional com a intensificação dos processos de globalização econômica e cultural e o papel crescente desempenhado pelos regimes e tribunais internacionais (GINSBURG; SHAFFER, 2009, p. 1, 21). Há um novo rumo empírico na erudição jurídica internacional. Com base em décadas de trabalho teórico em direito e ciências sociais, uma nova geração de estudos empíricos se propõe a entender como o direito internacional funciona em diferentes contextos. A tendência ao estudo empírico expandiu-se devido aos esforços de acadêmicos de várias áreas, com juristas desempenhando papéis centrais de forma independente (SHAFFER; GINSBURG, 2012, p. 1).

Esquematicamente, e da maneira mais objetiva possível, questiona-se: “A” produz “ $X$ ”, ou seriam "B” ou “C” mais propensos a produzir "X”? Na forma clássica de uma hipótese científica, em que "X" (variável dependente) é um aspecto da dignidade humana e da justiça e “A”, "B”, e "C" (variáveis independentes) são políticas públicas. Ademais, as questões que nos interessam devem ser de natureza essencialmente quantitativa. Assim, a política “A” ou "B" produz mais ou menos “ $X$ ”? E, para isso, precisamos fazer pleno uso de dados quantitativos disponíveis e nos esforçar para que mais dados se tornem disponíveis. Uma abordagem baseada na compreensão estreita de uma única disciplina seria claramente insuficiente. ${ }^{18}$ Assim, nossa tarefa como acadêmicos deve ser a

\footnotetext{
${ }^{18}$ Byers (2001, p. 7, 16, 215-216) toma como variável dependente "o uso da força” e afirma que os acadêmicos do direito internacional confinados em sua própria disciplina são incapazes de responder como ele gera obrigações. Essa questão demanda a consideração de fatores e elementos não jurídicos, ou seja, entender o direito internacional como (mas apenas como) uma parte do amplo sistema internacional e aplicar conceitos e métodos que, embora familiares a outras disciplinas, são-lhe estranhos. Apenas concebendo e estudando o mundo social como uma totalidade, e nos inspirando nos pensamentos, tradições e métodos de uma variedade de disciplinas, poderemos compreender as complexidades jurídicas, políticas e sociais do novo milênio do qual somos parte. Destarte, dentre os relevantes desenvolvimentos na disciplina do direito internacional, talvez o mais interessante diga respeito ao fato de um crescente, conquanto pequeno, número de acadêmicos do direito internacional recomendar a adoção de abordagens interdisciplinares, isto é, a incorporação de fatores não jurídicos às explicações sobre a ordem jurídica internacional.
} 
elaboração de estratégias internacionais que promovam a realização desses valores, abordando questões relevantes para a política consoante os cânones da pesquisa científica, e as ferramentas necessárias para a concretização desses objetivos vêm de diversas disciplinas (JACOBSON, 1982, p. 325, 328-330).

A essência do trabalho interdisciplinar é entender o outro a partir do interior da sua disciplina. No final, esse trabalho nos traz de volta para nossa própria disciplina. Os acadêmicos do direito internacional devem trabalhar, com os cientistas políticos, problemas de interesse comum, utilizando diferentes concepções de como o sistema internacional opera, para gerar ideias e argumentos sobre questões substantivas específicas, projetando melhores instituições e questionando seus próprios pressupostos sobre o que o direito internacional na verdade é e como ele funciona. Todavia, se muito foi dito sobre o que os acadêmicos do direito internacional devem fazer, é importante uma palavra sobre o que não devem fazer: ignorar o desejo de um mundo melhor. O direito e a política estão interligados em tal mundo, mas esse mundo precisa ser imaginado antes de ser construído. Essa veleidade pode ser compartilhada, mas nunca abandonada (SLAUGHTER, 2000, p. 233, 235).

As relações internacionais são de grande valor para o amplo papel social dos acadêmicos do direito internacional como construtores de políticas, ou ainda, como arquitetos da governança global. Ajudam-nos na análise teórica dos problemas sociais e no desenvolvimento de melhores respostas (ABBOTT, 2005, p. 10). Somos filhos do Iluminismo na medida em que acreditamos na melhora da vida humana pela ação guiada pelo conhecimento. Portanto, buscamos o conhecimento para desenvolver a qualidade da ação humana. Keohane (1988, p. 380) define o progresso humano em termos de bem-estar, liberdade e segurança dos indivíduos, com especial atenção aos princípios de justiça. Contudo, sem compreender a relação entre o direito internacional e as ações dos Estados, os especialistas não podem fornecer orientações políticas úteis. O bom funcionamento do sistema jurídico internacional exige uma teoria coerente do cumprimento do direito internacional (GUZMAN, 2002, p. 1826).

\section{CONSIDERAÇÕES FINAIS}

Não se propugna por uma disciplina comum entre o direito internacional e as relações internacionais, tampouco se alimenta a ilusão de que um dia haverá uma teoria geral do direito internacional e das relações internacionais capaz de prever os comportamentos dos Estados em circunstâncias específicas. O eldorado das verdades absolutas e das leis universais está sempre à 
espera dos tolos. O que, modestamente, busca-se é uma agenda de pesquisa colaborativa. Finda a tarefa de derrubar muros, começa a de construir pontes. Fruto do colapso da barreira intelectual e da insularidade acadêmica entre ambas as disciplinas, cabe agora que tenhamos, no mínimo, a elaboração de um vocabulário único que facilite o compartilhamento de ideias e informações.

Todo esse esforço é crucial para a qualidade do papel social dos estudiosos do direito e das relações internacionais como construtores de políticas públicas. Nossa tarefa como acadêmicos deve ser a confecção de estratégias internacionais dotadas de valores comprometidos com a melhora da vida humana. No entanto, despidos de uma idônea compreensão do fenômeno jurídico do cumprimento do direito internacional, nada disso será adequadamente alcançado.

\section{REFERÊNCIAS}

ABBOTT, Kenneth W. International law and international relations theory: building bridges. American Society of International Law Proceedings, v. 86, p. 167-171. 1992.

International relations theory, international law, and the regime governing atrocities in international conflicts. Studies in Transnational Legal Policy, v. 36, p. 127-158. 2004.

. Modern international relations theory: a prospectus for international lawyers. Yale Journal of International Law, v. 14, n. 2, p. 335-411. 1989.

. Toward a richer institutionalism for international law and policy. Journal of International Law and International Relations, v. 1, n. 1-2, p. 9-34. 2005.

ACEVES, William J. Institutionalist theory and international legal scholarship. American University Journal of International Law and Policy, v. 12, n. 2, p. 227-266. 1997.

ALKOBY, Asher. Theories of compliance with international law and challenge of cultural difference. Journal of International Law and International Relations, v. 4, p. 151-198. 2008.

AREND, Anthony Clark. Legal rules and international society. New York: Oxford University Press, 1999. 208 p.

BADIN, Michelle Ratton Sanchez; SILVA, Lucas Tasquetto da; SATO, Nathalie Suemi Tiba. As trilhas de Anne-Marie Slaughter na defesa da interdisciplinaridade entre Direito Internacional e Relações Internacionais. Direito GV Research Paper Series, n. 94, p. 1-25. 2014.

BECK, Robert J. International law and international relations scholarship. In: ARMSTRONG, D. (Org.). Handbook of International law. New York: Routhledge, 2009. p. 13-43.

International law and international relations: the prospects for interdisciplinary collaboration. Journal of International Legal Studies, v. 1, n. 2, p. 119-150. 1995. 
BEDERMAN, David J. Constructivism, positivism, and empiricism in international law. Georgetown Law Journal, v. 89, n. 2, p. 469-500. 2001.

BRADFORD, William C. International legal compliance: an annotated bibliography. North Carolina Journal of International Law and Commercial Regulation, v. 30, p. 379-428, 2004.

. International legal compliance: surveying the field. Georgetown Journal of International Law, v. 36, p. 495-536, 2005.

BRUNNÉE, Jutta; TOOPE, Stephen J. International law and constructivism: elements of an interactional theory of international law. Columbia Journal of Transnational Law, v. 39, n. 1, p. 1974. 2000.

BURLEY, Anne-Marie Slaughter. International law and international relations theory: a dual agenda. American Journal of International Law, v. 87, n. 2, p. 205-239. 1993.

BUZAN, Barry. From international to world society? English school theory and the social structure of globalisation. Cambridge: Cambridge University Press, 2006. 294 p.

BYERS, Michael. Custom, power and the power of rules: international relations and customary international law. Cambridge: Cambridge University Press, 2001. 250 p.

CHILTON, Adam; TINGLEY, Dustin. Why the study of international law needs experiments. Columbia Journal of Transnational Law, v. 52, p. 176-239. 2013.

ELIAS, Fernando Lopes Ferraz. A internacionalização do direito a partir de diferentes fenômenos privados de construção normativa. Revista de Direito Internacional, v. 11, n. 1, 2014, p. 116-133.

GINSBURG, Tom; SHAFFER, Gregory. How does international law work? What empirical research shows. Minnesota Legal Studies Research, Paper n. 9-54, p. 1-26. 2009.

GLENNON, Michael J. How international rules die. Georgetown Law Journal, v. 93, n. 3, p. 939992. 2005.

GOLDSMITH, Jack L.; POSNER, Eric A. The limits of international law. Oxford: Oxford University Press, 2005. 262 p.

GUZMAN, Andrew T. A compliance-based theory of international law. California Law Review, v. 90, p. 1823-1887. 2002.

HAFNER-BURTON, Emilie M.; VICTOR, David G.; LUPU, Yonatan. Political science research on international law: the state of the field. The American Journal of International Law, v. 106, p. 47-97. 2012.

HATHAWAY, Oona A. Between power and principle: a political theory of international law. Yale Law School Legal Scholarship Repository, p. 469-536, jan. 2005. 
; KOH, Harold Hongju. Foundations of international law and politics. New York: Foundation Press, 2005. 393 p.

HENKIN, Louis. How nations behave: law and foreign policy. 2. ed. New York: Columbia University, 1979. 400 p.

HURRELL, Andrew. Conclusion: international law and the changing constitution of international society. In: BYERS, Michael (Coord.). The role of law in international politics. New York: Oxford University Press, 2000. p. 327-347.

IRISH, Adam; KU, Charlotte; DIEHL, Paul F. Bridging the international law-international relations divide: taking stock of progress. Georgia Journal of International and Comparative Law, v. 41, n. 2, p. 357-388. 2013.

JACOBSON, Harold K. The global system and the realization of human dignity and justice. International Studies Quarterly, v. 26, n. 3, p. 315-332. 1982.

JOHNSTON, Douglas M. Functionalism in the theory of international law. Canadian Yearbook of International Law, v. 26, p. 3-60. 1988.

JOYNER, Christopher C. Crossing the great divide: views of a political scientist wandering in the world of international law. American Society of International Law Proceedings, v. 81, p. 385-391. 1987.

KAPLAN, Norton A.; KATZENBACH, Nicholas de B. The political foundations of international law. New York: John Wiley e Sons, 1961. 372 p.

KELSEN, Hans. Peace through law. Clark, New Jersey: The Lawbook Exchange, 2008. 155 p.

; TUCKER, Robert W. Principles of international law. 2. ed. New York: Holt, Rinehart \& Winston, 1967. $602 \mathrm{p}$

KEOHANE, Robert O. Compliance with international commitments: politics within a framework of law. American Society of International Law Proceedings, v. 86, p. 176-179. 1992.

. International institutions: two approaches. International Studies Quarterly, v. 32, n. 4, p. 379-396. 1988.

International relations and international law: two optics. Harvard International Law Journal, v. 38, p. 487-502. 1997.

KINGSBURY, Benedict. The concept of compliance as a function of competing conceptions of international law. Michigan Journal of International Law, v. 19, p. 345-372. 1998.

KLABBERS, Jan. The relative autonomy of international law or the forgotten politics of interdisciplinarity. Journal of International Law \& International Relations, v. 1, n. 1-2, p. 35-48. 2005. 
KOSKENNIEMI, Martti. Carl Schmitt, Hans Morgenthau, and the image of law in international relations. In: BYERS, M. (Org.). The Role of Law in International Politics: Essays in International Relations and International Law. Oxford: Oxford University Press, 2000. p. 17-34.

- From apology to utopia: the structure of international legal argument. Cambridge: Cambridge University, 2005. 683 p.

; LEHTO, Marja. The privilege of universality: international law, economic ideology and seabed resources. Nordic Journal of International Law, v. 65, n. 3-4, p. 533-556. 1996.

KRASNER, Stephen D. International law and international relations: together, apart, together? Chicago Journal of International Law, v. 1, n. 1, p. 93-100. 2000.

KRATOCHWIL, Friedrich. Rules, norms, and decisions: on the conditions of practical and legal reasoning in international relations and domestic affairs. Cambridge: Cambridge University Press, 1999. 317 p.

; RUGGIE, John Gerard. International organization: a state of the art on an art of the state. International Organization, v. 40, n. 4, p. 753-775. 1986.

MAGEN, Amichai. The shadow of enlargement: can the European neighbourhood policy achieve compliance? Columbia Journal of European Law, v. 12, n. 2, p. 383-428. 2006.

MUSHKAT, Roda. Dissecting international legal compliance: an unfinished odyssey. Denver Journal of International Law and Policy, v. 38, p. 161-192. 2010.

NEFF, Stephen C. A short history of international law. In: EVANS, Malcolm D. (Coord.). International law. 3. ed. Oxford: Oxford University Press, 2010. p. 3-31.

ONUF, Nicholas; TAULBEE, James. Bringing law to bear on international relations theory courses. Political Science \& Politics, v. 26, n. 2, p. 249-254. 1993.

RATNER, Steven R.; SLAUGHTER, Anne-Marie. Appraising the methods of international law: a prospectus for readers. Studies in Transnational Legal Policy, v. 36, p. 1-22. 2004.

ROCHESTER, J. Martin. The rise and fall of international organization as a field of study. International Organization, v. 40, n. 4, p. 777-813. 1986.

SCOBBIE, Iain. Wicked heresies or legitimate perspectives? Theory and international law. In: EVANS, Malcolm D. (Coord.). International law. 3. ed. Oxford: Oxford University Press, 2010. p. 58-92.

SHAFFER, Gregory; GINSBURG, Tom. The empirical turn in international legal scholarship. American Journal of International Law, v. 106, n. 1, p. 1-46. 2012.

SIMMONS, Beth A. Compliance with international agreements. Annual Reviews of Political Science, v. 1, p. 75-93. 1998. 
International law and international relations: scholarship at the intersection of principles and politics. American Society of International Law Proceedings, v. 95, p. 271-279. 2001.

Money and the law: why comply with the public international law of money? Yale Journal of International Law, v. 25, n. 2, p. 323-362. 2000.

SLAUGHTER, Anne-Marie. International law and international relations. Recueil dês Cours, v. 285, p. 9-249, 2000.

. International law in a world of liberal states. European Journal of International Law, v. 6, n. 4, p. 503-538. 1995.

SLAUGHTER, Anne-Marie; TULUMELLO, Andrew S.; WOOD, Stepan. International law and international relations theory: a new generation of interdisciplinary scholarship. American Journal of International Law, v. 92, n. 3, p. 367-397. 1998.

SOUZA, Igor Abdalla Medina de. Dom Quixote reencontra Sancho Pança: relações internacionais e direito internacional antes, durante e depois da guerra fria. Contexto Internacional, v. 28, n. 1, p. 101-166. 2006.

STERN, Brigitte. How to regulate globalization? In: BYERS, Michael (Coord.). The role of law in international politics. New York: Oxford University Press, 2000. p. 247-268.

TAUBMAN, Jarrett. Towards a theory of democratic compliance: security council legitimacy and effectiveness after Iraq. New York University Journal of International Law and Politics, v. 37, n. 1, p. 161-224. 2004.

TRIMBLE, Philip R. International law, world order, and critical legal studies. Stanford Law Review, v. 42, n. 3, p. 811-845. 1990.

VARELLA, M. D. Internacionalização do direito. Brasília: UniCEUB, 2013. 500 p.

VERDIER, Pierre-Hugues. Cooperative states: international relations, state responsibility and the problem of custom. Virginia Journal of International Law, v. 42, p. 839-867. 2002.

\section{LAW AND INTERNATIONAL RELATIONS FACING A JOINT DISCIPLINE, FROM INTERNATIONAL LEGAL COMPLIANCE}

ABSTRACT: The purpose of this article is to assess the possibility of building a joint discipline between Law and International Relations. Initially, we highlight the dilemmas and challenges of an eventual interdisciplinary fusion. We next consider the possibilities and prospects of a dialogue between the two areas. At the end, we investigate the method applied to the study of Law and International Relations. We found that epistemological and methodological obstacles prevent a complete integration between Law and International Relations. However, in order to investigate the influence of international norms on the behavior of international actors, a new empirical field for International Law is being uncovered, from the application of Social Sciences' methods and the revision of international relations theory. We should not seek a general theory of International Law 
AS RELAÇÕES INTERNACIONAIS E O DIREITO DIANTE DE UMA DISCIPLINA CONJUNTA, A PARTIR DOS MECANISMOS DE INDUÇÃO AO CUMPRIMENTO DAS NORMAS INTERNACIONAIS

and International Relations, but a collaborative research agenda, based on a common vocabulary between the two disciplines.

KEYWORDS: International Relations. International Law. Common Discipline. International Legal Compliance.

Recebido: 10 de fevereiro de 2015

Aprovado: 27 de abril de 2015 